Dr. S. M. Laird said that he understood that all Maj. Salaman's remarks referred to material from the genital tract of one or other sex, and he wished to ask whether the speaker had any experience of material from the extragenital lesions associated with gonorrhoea : for example, in a case of ophthalmia in which the gonococcus could not be found.

Maj. Salaman said that he was glad that this question had been asked, because he hoped to obtain some non-genital organisms. If any member would let him know when such strains had been isolated, he would be very grateful. He was not very hopeful that an ophthalmic strain would be fundamentally different from the others, but strains obtained on aspiration of the joints would be exactly suitable for purposes of comparison.

The President asked whether or not an attempt had been made to isolate the L organism in material from any of the metastatic manifestations of so-called non-gonococcal urethritis, or even from non-gonococcal ophthalmia in newborn babies.

Maj. Salaman said that he did not know of any attempt to grow such organisms.

\title{
VENEREAL DISEASE IN INDIA
}

\author{
By E. E. PREBBLE, M.D.
}

Assistant Venereal Diseases Medical Officer, Liverpool Royal Infirmary; Senior Assistant Venereal Diseases Medical Officer, Seamen's Dispensary, Liverpool; late Brigadier, A.M.S., Consultant Venereologist, India Command

Within a very short time of arrival in India the observant medical practitioner cannot fail to be dismayed by the deplorable lack of adequate public health facilities in a territory populated by approximately one-fifth of the total number of inhabitants of the world. It would be invidious to attempt to apportion the blame for this state of affairs. In fairness, one must say that the various medical authorities are by no means the sole offenders; other and much deeper causes have to be taken into consideration. In a land visited by such inflictions as malaria, cholera, typhoid fever and dysentery-and the number of cases of these diseases staggers the imagination-it is not to be wondered at that the subject of venereal diseases has been grossly neglected. That this is singularly unfortunate can hardly be doubted when one realizes the misery which such diseases can produce and the profound effect which they have on human life from conception to the grave.

The following observations are based on information gained during a residence of almost three years in India, during which time I visited on more than one occasion every important town in the entire subcontinent. This involved almost 100,000 miles of travel. My work was entirely concerned with the military side, but facilities were readily granted for me to visit all civil clinics in which the treatment of persons suffering from venereal disease was undertaken. For this opportunity I am indebted to the Director-General of the Indian Medical Service and to the Surgeons General and Civil Surgeons in the Provinces.

For convenience, the subject of the article is divided into two sectionsvenereal diseases in the Army and venereal diseases in the civil population-but there is a certain amount of inevitable overlapping and the second section deals almost entirely with the treatment of civilians.

\section{VENEREAL DISEASES IN THE ARMY : AN ANALYSIS OF OVER 70,000 CASES}

In an eastern country in which amenities-particularly so far as British troops were concerned-were totally inadequate, it was to be expected that the incidence of venereal diseases would be great. In the case of Indian troops, other factors came into play. The incidence of these diseases in Indian troops in peacetime is exceptionally low, owing to the fact that the troops are specially selected recruits, that they enjoy regular leave and that they are frequently stationed near to their 
homes. In wartime, however, the standards were much lower, leave was very irregular and troops were frequently stationed far from their homes ; for example, Madrassis might be stationed in Assam or on the North-west Frontier, and in either case were over 1,500 miles from their homes. Troops in wartime were in receipt of considerably more money than in normal times, and (apart from certain compulsory deductions) the average Indian soldier seldom saves money ; consequently the Indian soldier fell an easy prey to the prostitutes who abound all over the country. In view of the fact that no real facilities exist for the treatment of venereal diseases in civilians, it can be appreciated readily that a considerable proportion of these prostitutes are infected with venereal disease.

\section{Sources of infection}

(1) Brothels.-Almost all towns-and even the largest villages-have varying numbers and types of brothel. These houses vary in type from the exclusive brothel of the large cities, in which cleanliness exists and some form of unofficial medical examination takes place regularly, to the very lowest types, which are filthy and in which no precautions whatsoever are available, not even simple sanitary arrangements. Needless to say, it is not considered that the so-called medical examination is of any real value ; but the visit of a medical officer probably at least ensures ordinary cleanliness, which is most desirable. In one street with its small side courts in Calcutta there are hundreds of brothels with approximately 3,000 prostitutes regularly plying their trade. In Bombay there exists a street of brothels in which the women display themselves behind bars, rather like goods in a shop window or animals in a zoo. Various laws exist which prohibit brothels, but they are almost never invoked, chiefly on account of difficulty in accurately defining a brothel. The fees charged in the brothels vary from as much as 500 rupees ( $£ 3710$ s. $0 \mathrm{~d}$.) to 2 annas ( $2 \mathrm{~d}$.).

(2) Native women in country districts.-In the remoter districts there are numbers of women who act as clandestine prostitutes. Many-as for example the Khasi women in the hills near Shillong in Assam-are heavily infected with venereal disease. They are under the impression that if they become pregnant as a result of intercourse with Europeans they will strengthen their race ; as a result, an incredible situation arose in which they offered monetary inducement to the British troops who were stationed at or on leave in Shillong. This town is a delightful hill station at about 5,000 feet elevation and was a most popular leave centre. When the incidence of venereal disease reached quite considerable proportions, a civil clinic was opened and was heavily subsidized by the military authorities.

(3) Public solicitation.-Solicitation by women street-walkers, as we know it in the West, is very rare in India. The soldier, British or Indian, had very little difficulty, however, in finding the brothels. All were out of bounds, but they were so numerous that the Military Police were unable adequately to deal with the situation. Pimps and touts abounded wherever the troops were stationed or on leave, including those who sheltered behind their occupation as drivers of conveyances, as well as the more blatant type who strolled about the streets looking for likely customers.

\section{Prevention of infection}

It was the policy in India, as in other theatres of operations, to place all brothels out of bounds, on the assumption that such a step leads to a fall in the incidence of venereal disease. It was not possible to close all brothels or adequately to prevent access to them by the troops, for the reasons given above. Certain other factors, however, must always be taken into consideration if a low rate of incidence of infection is to be achieved. These are as follows.

(1) Good discipline and morale.

(2) Adequate amenities and facilities for recreation.

(3) Education.

(4) Instruction on the prevention of venereal diseases.

(5) Abolition of drunkenness. 


\section{VENEREAL DISEASE IN INDIA}

(6) Free distribution of preventive appliances.

(7) Efficient Provost-Marshal staff.

(8) Cooperation of unit officers.

Amenities in India lagged far behind those provided in other theatres of operations. This was singularly unfortunate, particularly in view of how little actually existed in the way of entertainment for European troops in India. It is true that in the final twelve months of World War II a much greater effort was made in this direction; the effort, however, ought to have been made very much earlier. Education and instruction were carried out by means of lectures, posters and films in English and in Urdu, the films being made in India specially for British and Indian troops serving in that country.

\section{Provision of treatment}

Treatment centres.- Special treatment centres for the diagnosis and treatment of venereal diseases by specialists were opened throughout India Command. These were geographically situated with a view to reducing, so far as was possible, the amount of travelling necessary to reach them. They were situated in Rawalpindi, Karachi, Bombay, Poona, Deolali, Secunderabad, Bangalore, Ernakulam (Cochin), Waltair, Avadi (Madras), Aurangabad, Lucknow, Lahore, Jullunder, Delhi, Jubbulpore, Bareilly, Calcutta, Ranchi, Asansol and Dacca ; centres in Gauhati and Chittagong were added later, when these areas returned to India Command.

Staff.-There were 103 medical officers employed whole time in the direction and treatment of venereal disease patients throughout India Command. They included a Consultant Venereologist stationed at G.H.Q. Delhi, and four Advisers in Venereology (one to each Army or Command) each of whom was attached to a large centre in his Army or Command, in which clinical work was undertaken by him in addition to his duties as Adviser to the Deputy Director of Medical Services, these entailing touring throughout his areas. There were also 20 Recognized Specialists, 48 Graded Specialists and 30 Trainees.

\section{Methods of treatment}

Prior to November 1944.-Gonorrhoea was treated with sulphapyridine until, as supplies became available, sulphathiazole was gradually substituted. Syphilis was treated with intravenous neoarsphenamine, together with intramuscular bismuth, either once or twice each week.

From the end of 1944 onwards.-Towards the end of 1944, limited supplies of penicillin became available for the treatment of venereal diseases. In the first instance, it was decided to use penicillin only in cases of chronic resistant gonorrhoea. Many of the patients treated-all sulphonamide-resistant and complicated cases - had been in hospitals for long periods of time. The results of penicillin therapy were dramatic, a very large proportion of these patients being cured in two or three days. It was obvious that we were dealing with a very potent substance. The situation in regard to supply improved rapidly ; within a month we were able to treat all cases of gonorrhoea with penicillin from the commencement of the disease. Results were again dramatic and the length of stay in hospital dropped from at least twelve days to two days, resulting in a great saving of hospital beds. Within another month or so it was found that the stock of penicillin was sufficient to justify its use in cases of syphilis. At first all early cases were treated and then, gradually, late cases were treated experimentally with increased dosage. The short-term results were excellent, but it has not been possible to follow up the cases for a sufficiently long period of time to enable us to assess the long-term results. A little later on, large numbers of patients were admitted for penicillin therapy who had been given arsenic and bismuth but who had not completed the course of treatment. These patients included many whose treatment had been grossly irregular on account of active service conditions; in many other cases neglect on the part of the patient or others had led to this irregularity.

Patients with gonorrhoea were treated with 100,000 Oxford units of penicillin, given as 10 injections of 10,000 units, or 5 injections of 20,000 units, at three-hourly intervals. 
Patients with syphilis were given 2,400,000 units in 60 doses of 40,000 units every 3 hours. In addition, a large-scale investigation was conducted to assess the value of various courses of treatment with penicillin alone, penicillin with arsenic and bismuth, and penicillin with bismuth. It is hoped that it may be possible to publish the results of this investigation at a later date.

TABLE 1.-ADMISSIONS TO MILITARY TREATMENT CENTRES IN INDIA

\begin{tabular}{|c|c|c|c|c|c|c|c|c|}
\hline \multirow{2}{*}{\multicolumn{5}{|c|}{ DISEASE }} & \multicolumn{2}{|c|}{ Number of patients } & \multicolumn{2}{|c|}{ Percentages } \\
\hline & & & & & \multirow{2}{*}{$\begin{array}{c}\text { British } \\
2,179\end{array}$} & \multirow{2}{*}{ Indian } & \multirow{2}{*}{$\frac{\text { British }}{12}$} & \multirow{2}{*}{$\begin{array}{c}\text { Indian } \\
31\end{array}$} \\
\hline Syphilis $\quad \ldots$ & $\ldots$ & $\ldots$ & $\cdots$ & $\ldots$ & & & & \\
\hline Gonorrhoea & $\ldots$ & ... & $\cdots$ & $\ldots$ & 5,051 & 10,012 & 28 & 18 \\
\hline Chancroid ... & $\ldots$ & $\ldots$ & $\ldots$ & $\ldots$ & 3,969 & 17,070 & 22 & 31 \\
\hline Urethritis ... & $\ldots$ & $\ldots$ & $\cdots$ & ... & 2,416 & 3,250 & $13 \cdot 5$ & 6 \\
\hline Lymphogranul & na i & ainale & $\cdots$ & $\cdots$ & 332 & 284 & 2 & 0.5 \\
\hline Balanitis $\quad \ldots$ & $\ldots$ & $\cdots$ & $\cdots$ & $\cdots$ & 738 & 473 & 4 & 1 \\
\hline Phimosis and & raph & osis & $\cdots$ & $\ldots$ & 73 & 169 & $0 \cdot 4$ & $0 \cdot 3$ \\
\hline Genital warts & $\ldots$ & $\ldots$ & $\cdots$ & $\cdots$ & 301 & 215 & $1 \cdot 7$ & $0 \cdot 4$ \\
\hline Stricture of th & Ireth & & $\ldots$ & $\cdots$ & 13 & 48 & $0 \cdot 1$ & $0 \cdot 1$ \\
\hline Prostatitis* & $\ldots$ & $\ldots$ & ... & $\cdots$ & 83 & 73 & 0.6 & 0.2 \\
\hline Epididymitis* & $\cdots$ & $\cdots$ & $\cdots$ & $\cdots$ & 89 & 136 & 0.6 & 0.4 \\
\hline Orchitis* $\quad \ldots$ & $\ldots$ & $\ldots$ & $\ldots$ & $\ldots$ & 37 & 114 & $0 \cdot 3$ & $0 \cdot 3$ \\
\hline Others & $\ldots$ & $\ldots$ & $\cdots$ & $\ldots$ & 2,441 & 5,240 & $14 \cdot 8$ & $10 \cdot 8$ \\
\hline Total ... & $\ldots$ & $\ldots$ & $\ldots$ & $\ldots$ & 17,722 & 54,171 & & \\
\hline
\end{tabular}

\section{Analysis of admissions to treatment centres}

From the accurate returns received for the nine months ending 31st October 1945 , it was found that a total of 71,943 patients were admitted for diagnosis and treatment to the venereal diseases treatment centres in India Command during that period; of this number British and Allied troops accounted for 17,722 cases and Indian troops for 54,171 cases.

From Table 1 it will be seen that syphilis is responsible for 12 per cent of all admissions to venereal diseases treatment centres in the case of British troops, and for 31 per cent in the case of Indian troops. Gonorrhoea, on the other hand, is responsible for 28 per cent of all admissions in the case of British troops and only 18 per cent in the case of Indian troops. Expressed somewhat differently, this calculation shows that in the case of British troops there are 2.3 cases of gonorrhoea to each case of syphilis, whereas in the case of Indian troops there are 1.7 cases of syphilis to every one of gonorrhoea. The explanation for this difference is somewhat obscure, but it is well known that the British soldier frequently makes use of prophylaxis (although it is often inadequate), whereas the Indian seldom does, also that the prophylactic packet affords a fair degree of protection against syphilis but little against gonorrhoea.

From Table 2 it will be seen that syphilis has reached the secondary stage in 11.2 per cent of British cases and $15 \cdot 2$ per cent in Indian cases before the patient reports at the treatment centre. These figures are disappointingly high. The incidence of secondary cases was due for the most part to lack of regular medical inspection, although it is quite probable that a certain proportion of the delay in treatment was due to actual concealment or to ignorance on the part of the patients.

The relapse rate for all patients treated for gonorrhoea with penicillin in the dosage already indicated, as shown in Table 3 , is 5.2 per cent in the case of British and 4.1 per cent in the case of Indian troops, giving an over-all average relapse rate of 4.4 per cent. The present tendency appears to be to treat gonorrhoea 
with a total dosage of between 150,000 and 200,000 Oxford units of penicillin, whereas in the period to which the figures quoted refer the dose consisted of 100,000 units only. It is questionable whether the larger dose is really necessary or is likely to result in a rate of cure higher than 96 per cent of all types of case.

The substitution of penicillin for sulphathiazole resulted in an immediate and very considerable reduction in the total number of beds occupied by patients with

TABLE 2-INCIDENCE OF SYPHILIS IN THE ARMY

\begin{tabular}{|c|c|c|c|c|c|c|c|c|}
\hline & \multirow{2}{*}{\multicolumn{4}{|c|}{ STAGE }} & \multicolumn{2}{|c|}{ Number of cases } & \multicolumn{2}{|c|}{ Percentages } \\
\hline & & & & & British & Indian & . British & Indian \\
\hline Primary & $\ldots$ & $\ldots$ & $\ldots$ & $\ldots$ & 1,827 & 13,852 & $83 \cdot 8$ & 81 \\
\hline Secondary ... & $\ldots$ & $\ldots$ & $\ldots$ & $\ldots$ & 244 & 2,600 & $11 \cdot 2$ & $15 \cdot 2$ \\
\hline Late & $\ldots$ & $\cdots$ & $\cdots$ & $\ldots$ & 108 & 635 & 5 & $3 \cdot 8$ \\
\hline Total ... & $\ldots$ & $\ldots$ & $\ldots$ & $\ldots$ & 2,179 & 17,087 & & \\
\hline
\end{tabular}

TABLE 3-INCIDENCE OF GONORRHOEA IN THE ARMY

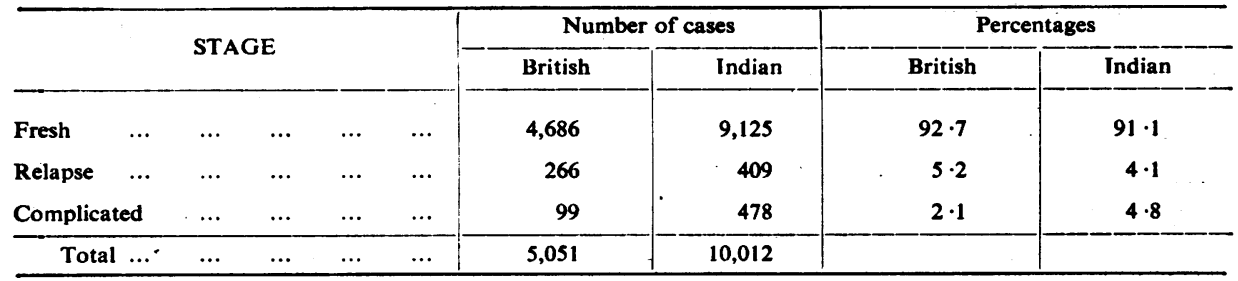

TABLE 4-RATIO OF SYPHILIS, GONORRHOEA AND CHANCROID IN THE ARMY

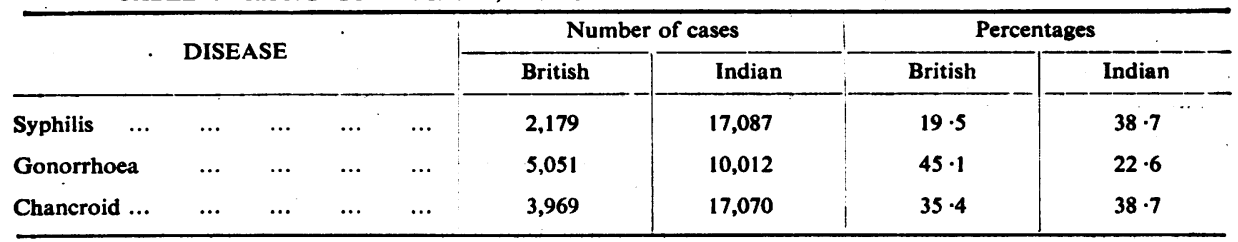

venereal diseases. What was not generally recognized was the enormous concentration of work that also resulted ; consequently, frequent demands for drastic reductions in staff had to be strongly opposed. The excellent work, often under difficult and trying conditions, performed by the Advisers in Venereology, Venereologists and Trainees working in the venereal diseases wards, as well as that of the Special Treatment Orderlies, deserves the highest praise.

\section{TREATMENT OF VENEREAL DISEASES IN THE CIVIL POPULATION}

Some typical venereal diseases clinics

I can state, without fear of contradiction, that there are very few clinics in India in which patients with these diseases are treated adequately and efficiently. One clinic alone, in the entire country, was found which could compare favourably with the better type of those existing in Great Britain. This clinic was adequately staffed, suitably housed and properly equipped, and it had a keen and experienced specialist in charge. The standard of work was high and the clinical material for teaching purposes was excellent. For the most part the very few clinics which exist appear to be serving little or no useful purpose whatsoever. In support of this statement two examples may suffice.

(1) In a large and important city in India there exists a venereal diseases clinic which forms a part of a large general hospital. The clinic building is of considerable size and has an imposing exterior. On entering the building, however, one cannot fail to be impressed by the indescribable squalor and by the obvious signs of complete lack of administrative experience in those responsible for its 
organization. The ground floor is occupied by small treatment rooms, a very large irrigation room and an equally large dressing room; there is no adequate waiting room. The upper floor consists of a large medical officers' room with the usual verandah on either side. The verandahs serve as waiting rooms for new patients, male on one side and female on the other. As the room is well provided with windows and as separate clinic hours for males and females do not exist, the resulting lack of privacy might have been considered to be embarrassing.

The irrigation room was so dirty, on the day of my visit, and the entire lack of sterilization facilities so obvious, that I felt sure that in any patient submitting to an irrigation a secondary infection of the urethra would be certain to develop very rapidly. The dressing room had a concrete floor with open drains, and in it about fifty patients were seen soaking penile sores, for which purpose they used tin cans, chiefly of the cigarette variety ; the process was entirely without supervision.

Arriving in the medical officers' room, we prepared to see some patients who were reporting for the first time. The first patient complained of a urethral discharge and the case was promptly diagnosed as gonorrhoee. An inquiry was made to find out whether or not a smear was to be taken, but I was informed that it was only of academic interest to do so, and that time did not permit of such refinements. The treatment ordered consisted of irrigations of a 1 in 8,000 solution of permanganate of potash. As the year was 1944, I asked whether sulphapyridine or sulphathiazole was not being given, but was informed that these medicaments were too expensive and that the hospital would not supply them. The next patient reported with a penile sore, which was carefully palpated and immediately diagnosed as syphilitic. I again asked whether a microscopic examination was not considered to be essential and was informed that, as the sore was indurated, this was not necessary and that in any case there was no time. A tentative suggestion was then made that perhaps a Wassermann reaction might give useful information, but I was informed that such a test cost 5 rupees $(7 \mathrm{~s} .6 \mathrm{~d}$.) and that the clinie could not afford it. The treatment ordered was 0.45 gramme of neoarsphenamine alone, by injection, and I learned that bismuth was not given in addition, as the clinic could not afford to give both. It was further argued that, in any case, arsenic was more potent than was bismuth; my informant reluctantly agreed, however, that a combination of the two did act better than either alone. On proceeding to the injection room, I discovered that the entire supply of neoarsphenamine for the morning's injections was already mixed and in solution, standing ready for use in a large open dish. A query concerning the wisdom of this practice elicited the reply that they never had any trouble.

From the above account it will be clearly seen that a patient reporting at this clinic cannot hope to be cured, for the average Indian suffering from gonorrhoea would never attend for a sufficiently long period of time to be cured by irrigation alone and a sufferer from syphilis would certainly cease to attend immediately his lesion was healed.

(2) In another clinic, in a smaller but very well known town, I was shown by a young and inexperienced doctor "an interesting case of secondary syphilis". The patient was stated to have had the lesions for six months. On inquiring whether or not scrapings from the lesions had been examined, I was informed that they had no facilities for such an examination. It was then suggested that a Wassermann reaction might be a useful diagnostic guide, but again I was informed that it was too costly. and was made use of only in doubtful cases. An examination of the patient soon showed that the alleged secondary syphilis was, in fact, seborrhoeic dermatitis ; it was therefore suggested that arsenic was not the ideal form of treatment for such a case. It was further recommended that a Wassermann test should be performed, regardless of expense, before arsenic or any other antisyphilitic treatment was undertaken.

These two examples are not isolated cases, but will, I believe, make it obvious that treatment facilities in India are entirely inadequate for the control of venereal disease. 
The clinics in Calcutta

Fortunately there is one brighter side to the very black picture. Up to the year 1943 no adequate treatment facilities existed in the city of Calcutta for the treatment of venereal diseases, a city with a population of not less than $4,000,000$. This city was a very popular leave centre with the large numbers of troops who were serving in the immediate neighbourhood and with those coming from all over Assam, Eastern Bengal and the borders of Burma. Amenities were totally inadequate, and it is not to be wondered at that large numbers of men contracted disease under these circumstances. Vice flourished almost unchecked in the second most populous city of the British Empire. It has been estimated that not less than 40,000 prostitutes lived in the city and, because they were scattered over a very considerable area, it was impossible for the provost-marshal's staff to deal with the situation. As a result of propaganda in Bengal, the Government of the Province, on 15th January 1944, decided to open seven clinics for the free treatment of venereal diseases for the civil population of Calcutta. A Director was appointed to supervise the working of the clinics and to be responsible for the training of medical officers to staff them. Five clinics were opened for the treatment of male patients, at the Medical College Hospital, Campbell Medical School Hospital, Sambhunath Pandit Hospital, Carmichael Medical College Hospital and the Chittaranjan Hospital, respectively. Unfortunately, it has not as yet been possible to obtain beds for in-patient treatment. In addition to the above, two clinics have been opened for the treatment of female patients, one at the Lady Dufferin Victoria Hospital and the other at Alipore Voluntary Venereal Hospital ; six beds are available at the former and 82 at the latter hospital for in-patient treatment of female patients.

TABLE 5-ATTENDANCES AT CALCUTTA CIVIL ClINICS, YEAR ENDING 31st DECEMBER 1944

\begin{tabular}{|c|c|c|c|c|c|c|c|c|}
\hline & & & & & & Males & Females & Total \\
\hline New cases & $\cdots$ & $\ldots$ & $\cdots$ & $\cdots$ & $\cdots$ & 26,337 & 4,265 & 30,602 \\
\hline Total attendances & $\ldots$ & ... & $\ldots$ & $\ldots$ & $\therefore$ & 181,872 & 24,619 & 206,491 \\
\hline
\end{tabular}

The Venereal Diseases Centre at the Medical College Hospital is a large, light and airy building, with separate cubicles for examination of patients in complete privacy, good waiting-room accommodation, an irrigation room, a minor operation room, a clinical side-room and other facilities. It is by far the largest of the clinics and deals with a considerable number of patients. The other clinics are, for the most part, very small and will certainly require extension in the very near future. The Alipore Voluntary Venereal Hospital is, in fact, an ad hoc clinic for the treatment of venereal diseases in women, and it appears to be doing excellent work. The treatment rooms are adequate and well furnished, and the wards are comfortable and are bright and cheerful. This is a matter of considerable importance in a city like Calcutta, which for ten months in the year enjoys a hot and humid climate. A large proportion of the patients admitted for in-patient treatment are prostitutes from the local brothels, and many are found to be suffering from at least two of the commoner venereal diseases. The standard of work at this clinic appeared to me to be high, and I felt that a most difficult problem was being tackled expeditiously and well. There is still room for improvement in all the clinics in Calcutta, but a most useful start has been made. Working, as they are, under incredibly difficult conditions, their results have been most gratifying, as the figures for the year ending 31st December 1944, given in Table 5, will show. This is a most encouraging start and should set an example for other Provinces to follow.

\section{Problems of organization}

Unfortunately, all public health problems are the prerogative of the Provincial 
Governments, and the Central Government merely acts in an advisory capacity, thereby making a coordinated policy almost impossible. There can be little doubt that a very great effort will be required if these entirely preventable diseases are to be brought under control. The great difficulty in the past has been the lack of suitably trained medical officers and medical orderlies. During World War II large numbers of Indian officers and orderlies were trained in the Army under ideal conditions, in modern treatment centres with adequate supplies of equipment and using the most modern forms of chemotherapy. For the most part; their services will not be required in the peace-time Army and they will be available for service in a post-war medical programme for the civil population of India. It will be a tragedy and an inestimable loss to India if they are not usefully employed. In the past remuneration has been pitifully small; this must be altered in the future.

Various estimates have been made of the incidence of venereal disease in the country generally, but none are in any way accurate. That the incidence is great can hardly be doubted. In one Province it was suggested that legislation should be introduced to make treatment compulsory, but it is my decided opinion that this would be a very serious mistake. It appears to be of little use to introduce legislation into a country which has almost no treatment facilities and in which the population is entirely ignorant of the nature of venereal diseases. It would appear, rather, to be necessary first of all to open free treatment centres on a large scale. In the first instance these should be in the larger cities, particularly the seaports; later on provision could be made for treatment in the smaller towns and villages, probably by means of travelling clinics. Secondly, it is essential to attempt to educate the people. This could be done by means of films and of radio talks and by eliciting the help of the newspapers. The uneducated Indian is much more likely to be influenced by films, which can be quite simple and must move at a slow pace; consequently this should be the method of approach.

The time is opportune and the results will pay handsome profits in the improved health and wellbeing of the population.

- Grateful acknowledgment is made of the help and encouragement of Lieutenant-General Gordon Wilson, Director of Medical Services in India.

\title{
EDITORIAL NOTES
}

The Editors beg to acknowledge with thanks the receipt of the following periodicals.

\author{
American Journal of Syphilis \\ Boletin medico-social \\ British Medical Journal \\ Crónica médica \\ Journal of the Cape Town Post-Graduate Medical Association \\ Journal of Experimental Medicine \\ Journal of Venereal Disease Information \\ Medical Times, New York \\ Medicina española \\ New England Journal of Medicine \\ Revista de la Asociacion médica argentina \\ Revista del Instituto de Salubridad y Enfermedades tropicales \\ Revista médica de Chile \\ Revista médica de Yucatan \\ South African Journal of Medical Sciences \\ Urologic and Cutaneous Review
}

